\title{
Metabolic characterization of aggressive breast cancer cells exhibiting invasive phenotype: impact of non-cytotoxic doses of 2-DG on diminishing invasiveness
}

Mayumi Fujita ${ }^{1 *}$, Kaori Imadome ${ }^{1}$, Veena Somasundaram ${ }^{3}$, Miki Kawanishi ${ }^{2}$, Kumiko Karasawa $^{2}$ and David A. Wink ${ }^{3}$

\begin{abstract}
Background: Metabolic reprogramming is being recognized as a fundamental hallmark of cancer, and efforts to identify drugs that can target cancer metabolism are underway. In this study, we used human breast cancer (BC) cell lines and established their invading phenotype (INV) collected from transwell inserts to compare metabolome differences and evaluate prognostic significance of the metabolome in aggressive BC invasiveness.

Methods: The invasiveness of seven human BC cell lines were compared using the transwell invasion assay. Among these, INV was collected from SUM149, which exhibited the highest invasiveness. Levels of metabolites in INV were compared with those of whole cultured SUM149 cells (WCC) using CE-TOFMS. The impact of glycolysis in INV was determined by glucose uptake assay using fluorescent derivative of glucose (2-NBDG), and significance of glycolysis, or tricarboxylic acid cycle (TCA) and electron transport chain (ETC) in the invasive process were further determined in aggressive BC cell lines, SUM149, MDA-MB-231, HCC1937, using invasion assays in the presence or absence of inhibitors of glycolysis, TCA cycle or ETC.

Results: SUM149 INV sub-population exhibited a persistent hyperinvasive phenotype. INV were hyper-glycolytic with increased glucose (2-NBDG) uptake; diminished glucose-6-phosphate (G6P) levels but elevated pyruvate and lactate, along with higher expression of phosphorylated-pyruvate dehydrogenase (pPDH) compared to WCC. Notably, inhibiting of glycolysis with lower doses of 2-DG (1 mM), non-cytotoxic to MDA-MB-231 and HCC1937, was effective in diminishing invasiveness of aggressive BC cell lines. In contrast, 3-Nitropropionic acid (3-NA), an inhibitor of succinate dehydrogenase, the enzyme that oxidizes succinate to fumarate in TCA cycle, and functions as complex II of ETC, had no significant effect on their invasiveness, although levels of TCA metabolites or detection of mitochondrial membrane potential with JC-1 staining, indicated that INV cells originally had functional TCA cycles and membrane potential.

(Continued on next page)
\end{abstract}

\footnotetext{
* Correspondence: fujita.mayumi@gst.go.jp

'Department of Basic Medical Science for Radiation Damages, National Institute of Radiological Sciences, NIRS, National Institute for Quantum and

Radiological Science and Technology, QST, 4-9-1, Anagawa, Inage-ku, Chiba-shi, Chiba-ken, Japan

Full list of author information is available at the end of the article
}

(c) The Author(s). 2020 Open Access This article is licensed under a Creative Commons Attribution 4.0 International License, which permits use, sharing, adaptation, distribution and reproduction in any medium or format, as long as you give appropriate credit to the original author(s) and the source, provide a link to the Creative Commons licence, and indicate if changes were made. The images or other third party material in this article are included in the article's Creative Commons licence, unless indicated otherwise in a credit line to the material. If material is not included in the article's Creative Commons licence and your intended use is not permitted by statutory regulation or exceeds the permitted use, you will need to obtain permission directly from the copyright holder. To view a copy of this licence, visit http://creativecommons.org/licenses/by/4.0/ The Creative Commons Public Domain Dedication waiver (http://creativecommons.org/publicdomain/zero/1.0/) applies to the data made available in this article, unless otherwise stated in a credit line to the data. 
(Continued from previous page)

Conclusions: Hyper-glycolytic phenotype of invading cells caters to rapid energy production required for invasion while TCA cycle/ETC cater to cellular energy needs for sustenance in aggressive BC. Lower, non-cytotoxic doses of 2-DG can hamper invasion and can potentially be used as an adjuvant with other anti-cancer therapies without the usual side-effects associated with cytotoxic doses.

Keywords: Breast cancer, Invasion, Metabolism, Glycolysis, TCA cycle, ETC, 2-DG

\section{Background}

Breast cancer $(\mathrm{BC})$ is a common cancer in women worldwide [1]. Although earlier diagnosis and improvements in treatment have reduced the mortality rate of $\mathrm{BC}$, the incidence of $\mathrm{BC}$ is estimated to be increasing globally [1]. Thus, prevention and treatment of $\mathrm{BC}$ remain a major public health concern. BC subtypes, such as inflammatory breast cancer (IBC) and triple negative breast cancer (TNBC), are aggressive types of $\mathrm{BC}$, which are extremely lethal and have higher potential for distant metastasis [2, 3]. Majority of BC patients succumb to metastasis. Thus, understanding the characteristics of the sub-population of cancer cells that exhibit the invasive phenotype is fundamental for discovering novel targets to block the invasion-metastasis cascade and ensure improved BC treatment.

Cancer cells adopt various strategies that allow them to be more aggressive such as changing their cellular metabolism [4]. Metabolic reprogramming is increasingly being recognized as a fundamental hallmark of cancer, and efforts to identify drugs that can target cancer metabolism are underway [5]. Several studies have revealed that oncogenes make cells more glycolytic [6, $7]$, and in fact, many tumor cells consume glucose and produce lactate at significantly higher rates than the surrounding tissue, even when enough oxygen exists $[8,9]$. 2-deoxy-D-glucose (2-DG), a D-glucose mimetic, inhibits glycolysis due to formation and intracellular accumulation of 2-deoxy-D-glucose-6-phosphate, inhibiting the function of hexokinase and glucose-6-phosphate isomerase [10, 11]. 2-DG has a potential application as an adjuvant for improving cancer therapy, as it was to be able to reduce cancer cell viability [12-15] and has also been assessed in several clinical studies as an anticancer agent [16-18]. However, clinical use of 2-DG still has been carefully studied because of its side effects [11, 14]. Thus, combination of lower dose of 2-DG with other anticancer drugs, or with radiotherapy, is promising for clinical use [11]. A recent report showed that 2-DG is also effective in inhibiting migration and invasion ability of an invasive subclone of the TNBC cell line, Hs578T [19]. Due to limited therapeutic options for targeting metastasis, use of 2-DG for blocking cancer invasiveness is attractive. However, the study only showed the result of one BC cell line, Hs578T, and thus, further studies are required to clarify the role of glycolysis in BC invasion.

It was originally hypothesized that cancer cells utilize aerobic glycolysis because of mitochondrial respiratory dysfunction [20]. However, later evidence suggested that most tumor cells have functional tricarboxylic acid (TCA) cycle and electron transport chain (ETC), despite which, cancer cells favor the use of glucose to produce lactate rather than acetyl-CoA for TCA cycle [4, 20, 21]. Glutamine can be a primary source of citrate via reductive metabolism and is known to be used as a source of TCA metabolites in aggressive cancers [22, 23]. In addition, several reports have revealed that mitochondria, the site of TCA cycle and ETC, is an important organelle that destines a cell to a metastatic phenotype $[24,25]$. Thus, it is still controversial which metabolic arm i.e., glycolysis or, TCA and ETC is significant for maintaining the invasive potential in $\mathrm{BC}$.

Herein, we establish that BC invasive cells (INV) collected from transwell inserts is a discernible population with a persistent phenotype that are hyperinvasive. These cells showed upregulation of glucose uptake and were effectively targeted using 2-DG. This effectiveness of 2-DG on blocking invasion was observed in several aggressive BC cell lines, SUM149 (IBC), MDA-MB-231 (TNBC), and HCC1937 (BRCA1mut/TNBC), and of note, low dose of 2-DG (1 mM), non-toxic to MDA-MB231 and HCC1937 viability, was effective in reducing their invasion. In contrast, blocking function of TCA cycle and ETC had no significant effect on their invasiveness, although levels of TCA metabolites or detection of mitochondrial membrane potential with JC-1 staining indicated that INV cells originally had functional TCA cycles and membrane potentials. Overall, our results convincingly establish that inhibition of glycolysis, such as with low dose of $2-\mathrm{DG}$, is a viable therapeutic option to blocking aggressive $\mathrm{BC}$ invasiveness.

\section{Methods}

Cell culture and reagents

Human BC cell lines, MCF-7 (ATCC ${ }^{\bullet}$ HTB-22), BT-474 (ATCC ${ }^{\oplus}$ HTB-20), SK-BR-3 (ATCC ${ }^{\ominus}$ HTB-30), MDAMB-468 (ATCC ${ }^{\oplus}$ HTB-132), MDA-MB-231 (ATCC HTB-26), HCC1937 (ATCC ${ }^{\ominus}$ CRL-2336) derived from different breast cancer subtypes were purchased from 
ATCC (Manassas, VA, USA), and SUM149 (Asterand SUM-149PT) from Asterand (Hertfordshire, UK) in 2013.The cell lines were authenticated by provider with morphology, karyotyping, and PCR based approaches. The subtypes of each cell lines were further authenticated with determining ER, PgR and HER2 expression in a recent paper [26]. Cells were cultured in complete RPMI (Roswell Park Memorial Institute) medium (Nakalai, Kyoto-shi, Kyoto-fu, Japan) consisting of $10 \%$ fetal bovine serum (FBS, HyClone Laboratories, GE Healthcare, Logan, UT, USA), 2 mM L-glutamine, and $100 \mathrm{U} /$ $\mathrm{ml}$ penicillin/streptomycin (Gibco, Gaithersburg, MD, USA) at $37^{\circ} \mathrm{C}$ and $5 \% \mathrm{CO}_{2}$. Cells in logarithmic growth phase were seeded at an appropriate density, and used for all experiments. 2-deoxy-D-glucose (2-DG) (SigmaAldrich, St. Louis, MO, USA), 3-Nitropropionic Acid (3NA) (Cayman Chemical, Ann Arbor, MI, USA), CB-839 (Cayman Chemical), Phloretin (Tokyo Chemical Industry, Nihonbashi, Tokyo, Japan) were the inhibitors used in this study.

\section{Transwell invasion assay}

The invasive potential of seven BC cell lines were examined as previously described [27-29]. The transwell membrane was photographed under bright field using a BZ-9000 fluorescence microscope (Keyence, Osaka, Japan) using a Nikon Plan Apo 4x/0.2 lens. Numbers of invaded cells in each field were counted with the particle counting application of ImageJ software (Version 1.52q) [27].

For inhibitor studies, cells were pre-treated with 2-DG, 3-NA, or CB-839 for $16 \mathrm{~h}$, trypsinized, suspended in serum-free RPMI with appropriate inhibitor, and then used for the invasion assay. Inhibitor was also added to the lower well, and the invasion assay was performed for $24 \mathrm{~h}$. In addition, surviving fraction of cells treated with each inhibitor for $16 \mathrm{~h}$ was examined by counting viable cells using trypan blue staining.

\section{INV preparation and re-invasion assay}

To prepare the invaded cells of SUM149 (INV), transwell invasion assays were performed as described previously $[28,29]$. For the re-invasion assay, WCC and INV were both cultured for $1,4,7,12$, or 19 days, and the transwell invasion assay was performed repeatedly with these cells as described previously [29].

\section{Sample preparation and metabolome analysis by CE- TOFMS}

INV and WCC $\left(1 \times 10^{\wedge} 5\right.$ cells/sample for INV, and $1 \times$ $10^{\wedge} 6$ cells/sample for WCC, respectively) were used for the extraction of intracellular metabolites [28], and the metabolome analysis was performed with CE-TOFMS as described earlier [28, 30-32]. The collection methods of
INV and WCC for the metabolome analysis were summarized in reference [28]. Analysis of raw data measured by CE-TOFMS was performed as described previously $[28,33]$.

\section{Immunoblotting}

Immunoblotting was performed as described previously [34]. Briefly, cells were lysed in $2 \times$ Laemmli sample buffer, followed by electrophoresis using the Novex $^{\circ}$ NuPAGE ${ }^{\circ}$ SDS-PAGE Gel system (ThermoFisher Scientific, Waltham, MA, USA). Primary antibodies against Pyruvate Dehydrogenase E1-alpha subunit (9H9AF5) $(\mathrm{PDH})$, phosphorylated-Pyruvate Dehydrogenase E1alpha subunit Ser300 (pPDH S300), Ser232 (pPDH S232), or Ser239 (pPDH S239) (Abcam, Cambridge, UK) were used along with horseradish peroxidase-conjugated anti-mouse IgG or anti-rabbit IgG (Amersham Biosciences; Buckinghamshire, UK). Bands were detected by enhanced chemiluminescence and visualized with a Lumino image analyzer, LAS 4000 (Fujifilm, Tokyo, Japan) using the ImageQuant LAS 4000 Control Software.

\section{Flow cytometry}

In order to examine the glucose uptake into living cells, 2-NBDG (2-Deoxy-2-[(7-nitro-2,1,3-benzoxadiazol-4yl)amino]-D-glucose, Cayman Chemical), a fluorescent derivative of glucose, was used. For WCC, cells were separately cultured as 3 groups; control, 2-NBDG treating, or 2-NBDG + Phloretin (inhibitor for the glucose transporter) treating groups. On the day of flow cytometry experiment, cells were washed with PBS and medium were changed to fresh RPMI supplemented with $0.5 \%$ FBS with or without $100 \mu \mathrm{M}$ Phloretin. After $4 \mathrm{~h}$ incubation, $60 \mu \mathrm{M}$ 2-NBDG was added to 2-NBDG group, and 2-NBDG + Phloretin group, and were incubated another $1 \mathrm{~h}$. Cells were then washed with PBS, incubated with Accutase for $15 \mathrm{~min}$ (Innovative Cell Technologies Inc.), collected and used for flow cytometry analysis in accordance with the manufacturer's instructions (CytoFLEX S with Analysis Software; Beckman Coulter). For INV, invasion assay was performed 1 day before the flow cytometry experiment. After $24 \mathrm{~h}$ INV cells underneath the transwell were directly treated with 2-NBDG or 2NBDG + Phloretin. WCC were also subjected to same treatment groups. Cells were collected with Accutase for $15 \mathrm{~min}$ and used for the flow cytometry analysis.

\section{Immunofluorescence study and image acquisition}

Immunofluorescence study, and image acquisition were performed with some modifications from previous studies [27]. Briefly, cells were cultured on glass slide chamber with phenol red free RPMI at appropriate density. On the day of immunofluorescence experiment, cells 
were washed with PBS, and medium was changed to fresh phenol red free RPMI with or without 3-NA. After $5 \mathrm{~h}$ incubation at $37^{\circ} \mathrm{C} / 5 \% \mathrm{CO}_{2}, 5,5^{\prime}, 6,6^{\prime}$-tetrachloro$1,1^{\prime}$, tetraethylbenzimidazolocarbocyanine iodide (JC-1, mitochondrial membrane potential detection indicator, ThermoFisher Scientific) and NucBlue ${ }^{\circ}$ Live ReadyProbes (Nuclear staining solution, ThermoFisher Scientific) were added to each well, and incubated for $30 \mathrm{~min}$. Cells were washed with PBS and fresh phenol red free RPMI was added, and images were acquired using a BZ9000 fluorescence microscope (Keyence, Osaka, Japan) using a 10X Planfluor NA 0.30 Ph1 lens with BZ filters for TRITC, GFP-B, and DAPI. Images were uniformly processed in Creative Cloud Photoshop CC using the brightness and contrast tools.

\section{Lactate measurement}

Cells were separately cultured as 3 groups; control, 0.3 mM 2-DG treatment, or $1 \mathrm{mM}$ 2-DG treatment groups. On the day before the experiment, cells were washed with PBS and medium was changed to fresh RPMI with appropriate concentration of 2-DG. After $16 \mathrm{~h}$ incubation, conditioned medium was collected and used for the assay according to the manufacture's protocol (Lactate Assay Kit-WST, Dojindo).

\section{Spheroid invasion assay}

Spheroid invasion assay was performed in ultra-low attachment multiple 96 well plates (Sigma-Aldrich) [28, 29]. Cells $\left(5 \times 10^{\wedge} 3\right)$ were plated in each well and incubated in $37^{\circ} \mathrm{C} \mathrm{CO}_{2}$ incubator. After $48 \mathrm{~h}$, spheroids were stained with JC-1 (1:50 concentration) for $30 \mathrm{~min}$, embedded into phenol red-free collagen solution (custom version 3D Ready Atelocollagen, KOKEN CO., LTD., Bunkyo-ku, Tokyo, Japan), followed by $1 \mathrm{~h}$ incubation at $37^{\circ} \mathrm{C} / 5 \%$ $\mathrm{CO}_{2}$ to allow solidification of collagen solution. Image of spheroid was captured at $1 \mathrm{~h}$ and $24 \mathrm{~h}$ after embedding into collagen gel and fluorescence was detected and photographed with a BZ-9000 fluorescence microscope using a $4 \mathrm{X}$ PlanApo $\lambda$ NA 0.20 lends with BZ filters for TRITC, GFP-B (Keyence, Osaka, Japan). Representative images were uniformly processed in Adobe Photoshop using the brightness and contrast tools.

\section{Statistical analysis}

All results are shown as the mean $+/-$ SD. Significance was analyzed using unpaired Student's t-test. $P$ value < 0.05 was considered significant.

\section{Results}

SUM149 showed the highest, persistent invasiveness among seven human $\mathrm{BC}$ cell lines

To investigate the role of glycolysis, or TCA cycle and ETC in the invasive ability of BC cells, we first planned to establish BC invaded cells collected from transwell inserts (INV) as we previously reported with human pancreatic cancer cells [29]. Number of cells which successfully invade through the Matrigel, vary depending on the cell line used for the invasion assay; some cell lines show no invading cells, while other cell lines have an evident proportion of invading cells. In order to prepare BC INV, we first had to choose the appropriate cell line, with a good number of invading cells, for collecting INV from transwell inserts. Thus, we used seven human $\mathrm{BC}$ cell lines to compare their invasiveness. Cell lines that originated from aggressive $\mathrm{BC}$ such as MDAMB468, MDA-MB-231, HCC1937 (TNBC cell lines), or SUM 149 (IBC cell line) exhibited intermediate to high invasiveness, with $0.70 \% \pm 0.25,3.07 \% \pm 0.41,3.66 \% \pm$ 0.26 , and $8.80 \% \pm 2.41$ invaded cells respectively. In contrast, less aggressive BC cell lines such as MCF-7 (Luminal-HER2 negative type), BT-474 (Luminal-HER2 positive type), or SK-BR-3 (HER2 positive type) showed minimal to no invasiveness $(0.00,0.00 \%$, or $0.14 \% \pm 0.02$, respectively) (Fig. 1a-b). Among the seven cell lines, SUM149 was selected for collecting INV, because it exhibited the highest number of invaded cells. To examine whether SUM149 INV had higher invasive phenotype compared to whole cultured SUM149 (WCC), a reinvasion assay was performed. Day1 collected INV from the undersurface of transwell membranes showed $1.65 \pm$ 0.11 times higher invasiveness compared to WCC. This increased invasiveness of INV was sustained until Day 19; being $1.71 \pm 0.27$ times higher on Day $4,1.89 \pm 0.47$ times higher on Day 7, $1.77 \pm 0.46$ times higher on Day 12 , and $1.73 \pm 0.29$ times higher on Day 19 (Fig. 1c), indicating that INV had persistently higher invasiveness compared to WCC. Thus, we used INV and WCC from SUM149 for further study, comparing the levels of glycolysis and TCA cycle metabolites.

\section{SUM149 invaded cells showed hyper-glycolytic phenotype compared to WCC}

SUM149 INV and SUM149 WCC were collected, and metabolites in these cells were analyzed by CE-TOFMS (Supplemental Table 1). PCA indicated that the metabolomic profile of INV was very distinct from that of WCC (Fig. 2a). Importantly, the glycolytic intermediate, glucose-6-phosphate (G6P), was below detection limit in INV, whereas the downstream metabolites, pyruvate and lactate were both increased compared to those of WCC, suggesting that INV metabolized glucose into lactate more efficiently/ faster than WCC did (Fig. 2b). Also, a portion of the G6P in WCC is used up in the production of glycerol-3-phosphate (G3P).

Pyruvate dehydrogenase (PDH) is a component enzyme of the pyruvate dehydrogenase complex, which catalyzes conversion of pyruvate to acetyl-CoA, the entry 

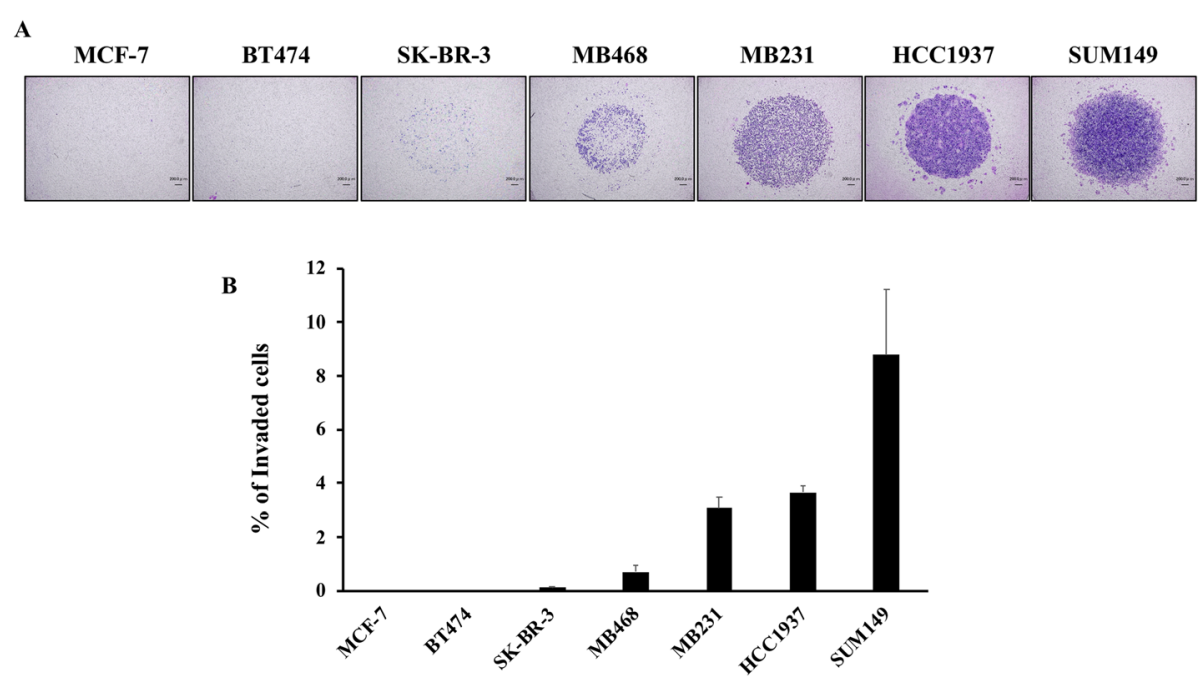

C

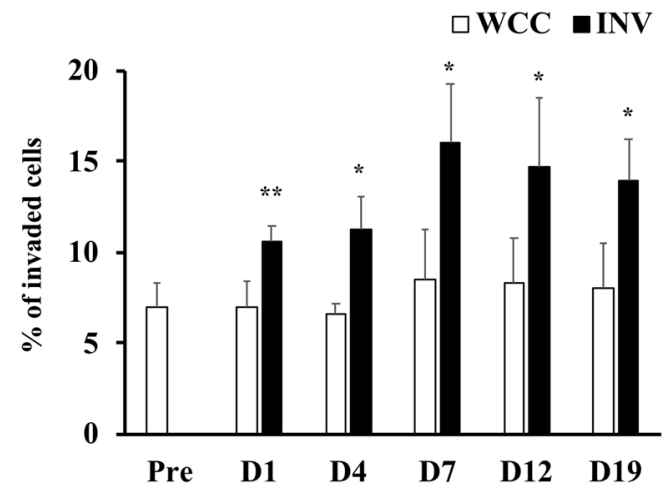

Fig. 1 SUM149 was selected for collecting invaded cells from transwell inserts. a Invasion assay was performed with using seven human breast cancer cell lines, MCF-7, BT-474, SK-BR-3, MDA-MB-468, MDA-MB-231, HCC1937, and SUM149. Representative images of invaded cells reached underneath of the transwell membrane are shown. Scale bar: $200 \mu \mathrm{m}$. b Percent of invaded cells of seven human breast cancer cell lines is shown in graph. Data are presented as mean \pm SDs of triplicate samples. c Whole cultured SUM149 cells (WCC) and INV collected from underneath of transwell membranes were used for invasion assay. Number of invaded cells were counted, and ratio of invaded cells of INV group to WCC group was summarized in graph. Data are presented as mean \pm SDs of triplicate samples. ${ }^{*} p<0.05,{ }^{* *} p<0.01$

substrate for the TCA cycle, rather than converting pyruvate into lactate [35]. De-phosphorylation of specific serine residues of the E1-alpha subunit of PDH, Ser300 (pPDH S300), Ser232 (pPDH S232), or Ser239 (pPDH S239), activates the conversion of pyruvate to acetyl CoA, whereas phosphorylation inactivates the enzyme, resulting in increased conversion into lactate. We found that the expression of pPDH S300, pPDH S232, and pPDH S239 were all significantly increased in INV compared to WCC (Fig. 3a-b, Supplemental Figure 1A-C), suggesting that $\mathrm{PDH}$ enzyme activity was reduced in INV, consistent with increased production of lactate (Fig. 2b). In addition, uptake of 2-NBDG, a fluorescent tracer used for monitoring glucose uptake into live cells, was higher in INV compared to WCC, and this was reduced by the addition of phloretin, a natural phenol which inhibits a variety of transporters including sodium/D-glucose cotransporter, SGLT1, which is known as the sodium-dependent glucose transporter [36] (Fig. 3c-e). Overall, these data indicated that INV had impaired PDH activity and consumed higher amount of glucose and metabolized it into lactate than WCC did.

\section{SUM149 invaded cells showed functional TCA cycle and ETC system but these pathways do not contribute to BC invasion}

Despite the higher rate of glycolysis and reduced conversion of glucose into acetyl-CoA in INV, the level of TCA cycle metabolites, such as citrate, succinate, and malate, were still higher in INV than WCC (Fig. 4), indicating that TCA cycle was functional in INV and was potentially being fueled by other sources. Additionally, to examine ETC in INV, we stained 2-day old SUM149 spheroids with JC-1, a mitochondrial membrane potential $(\Delta \Psi \mathrm{m})$ indicator. Red-stained cells (high $\Delta \Psi \mathrm{m})$ appear to be moving outward from the spheroid and 
A

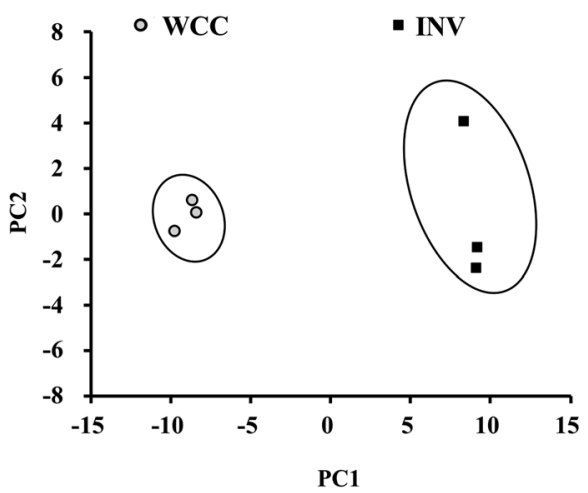

B

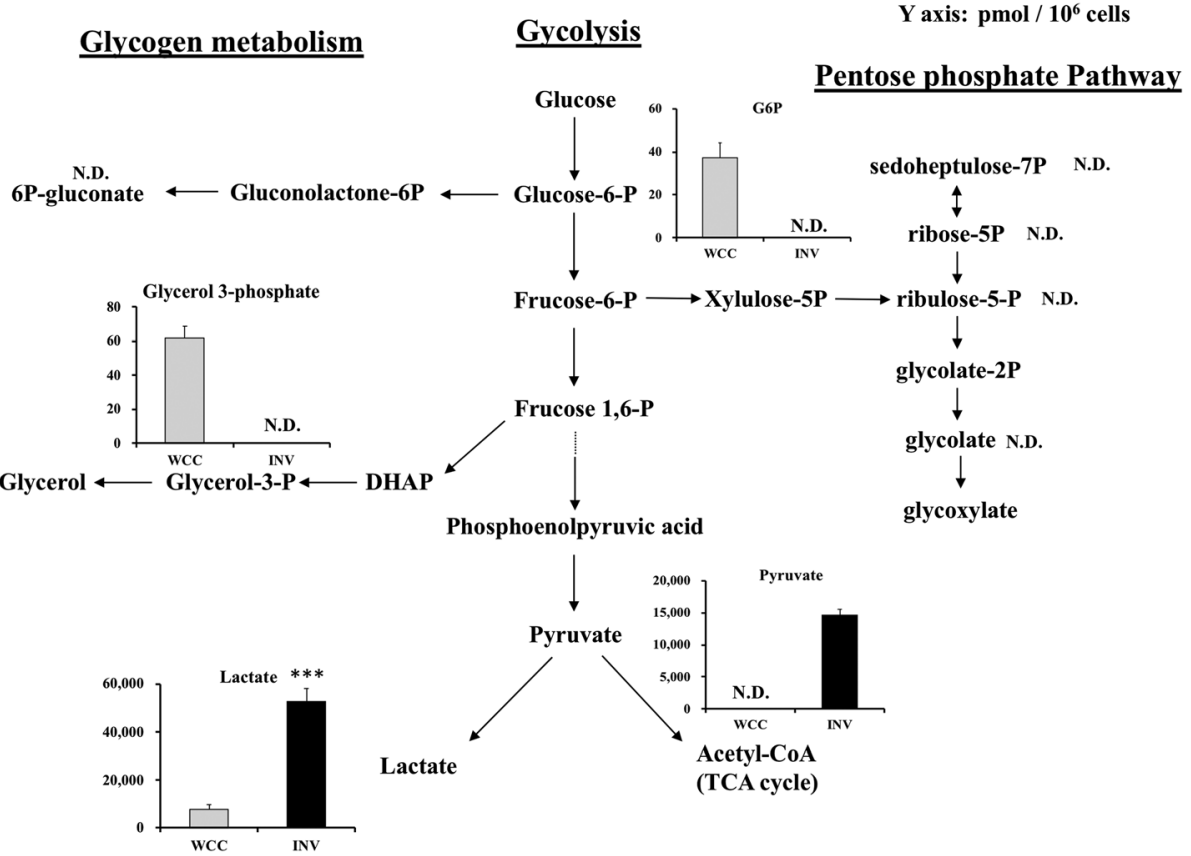

Fig. 2 SUM149 INV cells showed hyper-glycolytic phenotype compared to WCC. a Principal component analysis of metabolites detected in WCC versus INV was performed and is shown in the graph $(n=3)$. $\mathbf{b}$ Metabolomics profile of WCC and INV were analyzed by CE-TOFMS. The concentrations of glycolytic intermediates measured in WCC or INV are shown in graph. Y axis represents the metabolite concentration in pmol / $10 \wedge 6$ cells. Data are presented as mean \pm SD of samples $(n=3)$. ${ }^{* * *} p<0.001$ vs. WCC., N.D.: Not detected

invading the collagen gel, and green-stained cells (low $\Delta \Psi \mathrm{m})$ tend to stay within/ near the spheroid (Supplemental Figure 2), suggesting that SUM149 invading cells possess active mitochondria with high membrane potential. High mitochondrial membrane potential is generated by the reductive transfer of electrons through ETC protein complexes I-IV, which provides the energy to drive protons against their concentration gradient across the inner mitochondrial membrane [37]. Thus, SUM149 INV cells, which exhibited the active mitochondria, would also have a functional ETC system.

To investigate the role of TCA cycle and ETC in BC invasiveness, we next performed invasion assay with 3-
NA, an inhibitor of succinate dehydrogenase, the enzyme that oxidizes succinate to fumarate in the TCA cycle, and functions as complex II of the ETC [38]. Hence, 3-NA simultaneously inhibits TCA cycle and ETC. Interestingly, use of 3-NA had no significant effects on invasiveness of SUM149, MDA-MB-231, or HCC1937 (Fig. 5a-c), although their mitochondrial membrane potential was reduced with 3-NA treatment (Supplemental Figure 3A-C), suggesting that TCA cycle and ETC are less important for their invasive capability. In addition, since INV seemed to produce lactate rather than acetyl-CoA, glutamine from media or produced by anaplerotic reactions may be the source of fuel for TCA 
A

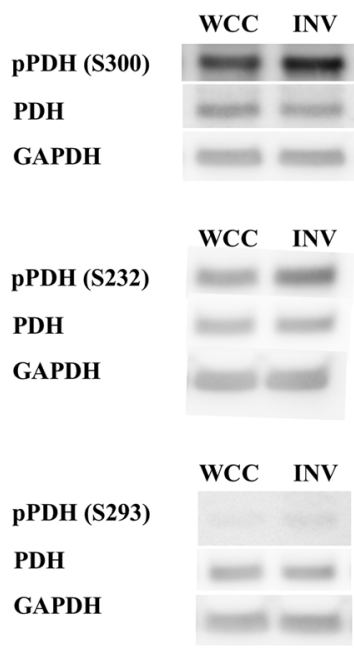

B
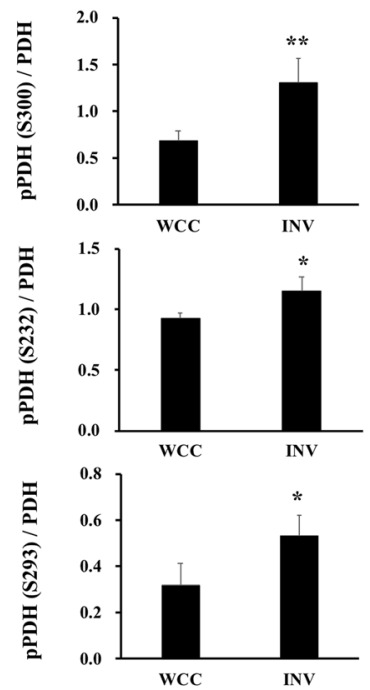

C

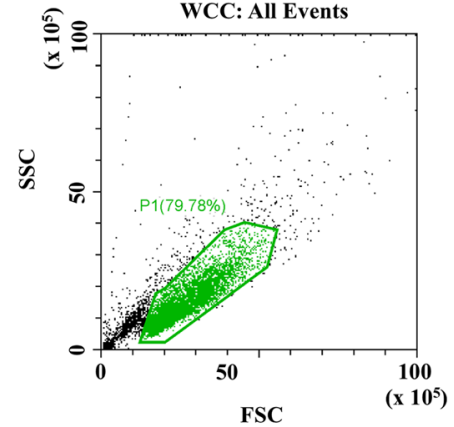

D

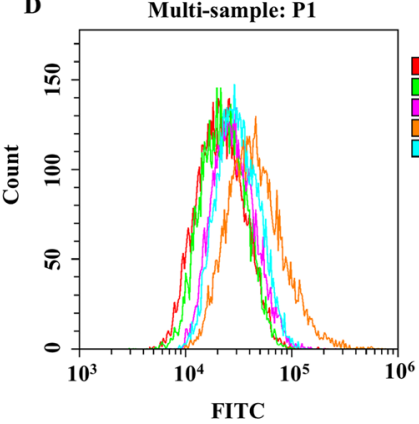

WCC

INCC 2-NBDG

WCC 2-NBDG

INV 2-NBDG + Phlo

E

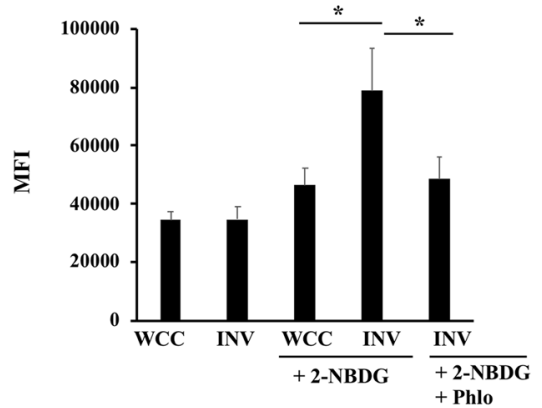

Fig. 3 Phosphorylation of PDH was increased in SUM149 INV compared to WCC Expression of pPDH S300, pPDH S232, pPDH S239, PDH, and GAPDH proteins of INV and WCC were examined with western blot analysis and bands were shown in (a), and the graphs of phosphorylatedPDH vs. pan-PDH were shown in (b). Data are presented as mean \pm SD of samples $(n=3) .{ }^{*} P<0.05$, ${ }^{* *} P<0.01$ vs. WCC. Uncropped full-length blots images were shown in Supplemental Figure 1. c Glucose uptake into WCC or INV was examined with 2-NBDG, and analyzed with flow cytometer. Live cells were gated as P1 (c), and levels of FITC and mean fluorescent intensity (MFI) was shown in graph (d), and (e), respectively. 2NBDG represents a fluorescent tracer used for monitoring glucose uptake, and Phlo represents phloretin, inhibitor for the glucose transporter, respectively. Data are presented as mean \pm SD of samples $(n=3) .{ }^{* *} p<0.01,{ }^{* * *} p<0.001$

cycle via reductive metabolism to $\alpha$-ketoglutarate $[22$, 23], as glutamine and glutamic acid levels were also higher in INV compared to WCC (Fig. 4, Supplemental Figure 4A-B). Thus, we next performed SUM149 invasion assay using glutamine-free medium, or Glutaminase 1 (GLS1) inhibitor, CB-839. However, use of Glutamine free medium or CB-839 had no significant effects on reducing their invasion (Supplemental Figure 5A-B). Overall, these data suggested that TCA cycle and ETC system are less significant for $\mathrm{BC}$ invasion.

\section{Glycolysis inhibitor diminished BC invasion}

In order to examine the role of glycolysis in $\mathrm{BC}$ invasion, we next used glycolysis inhibitor, 2-DG, for the invasion 


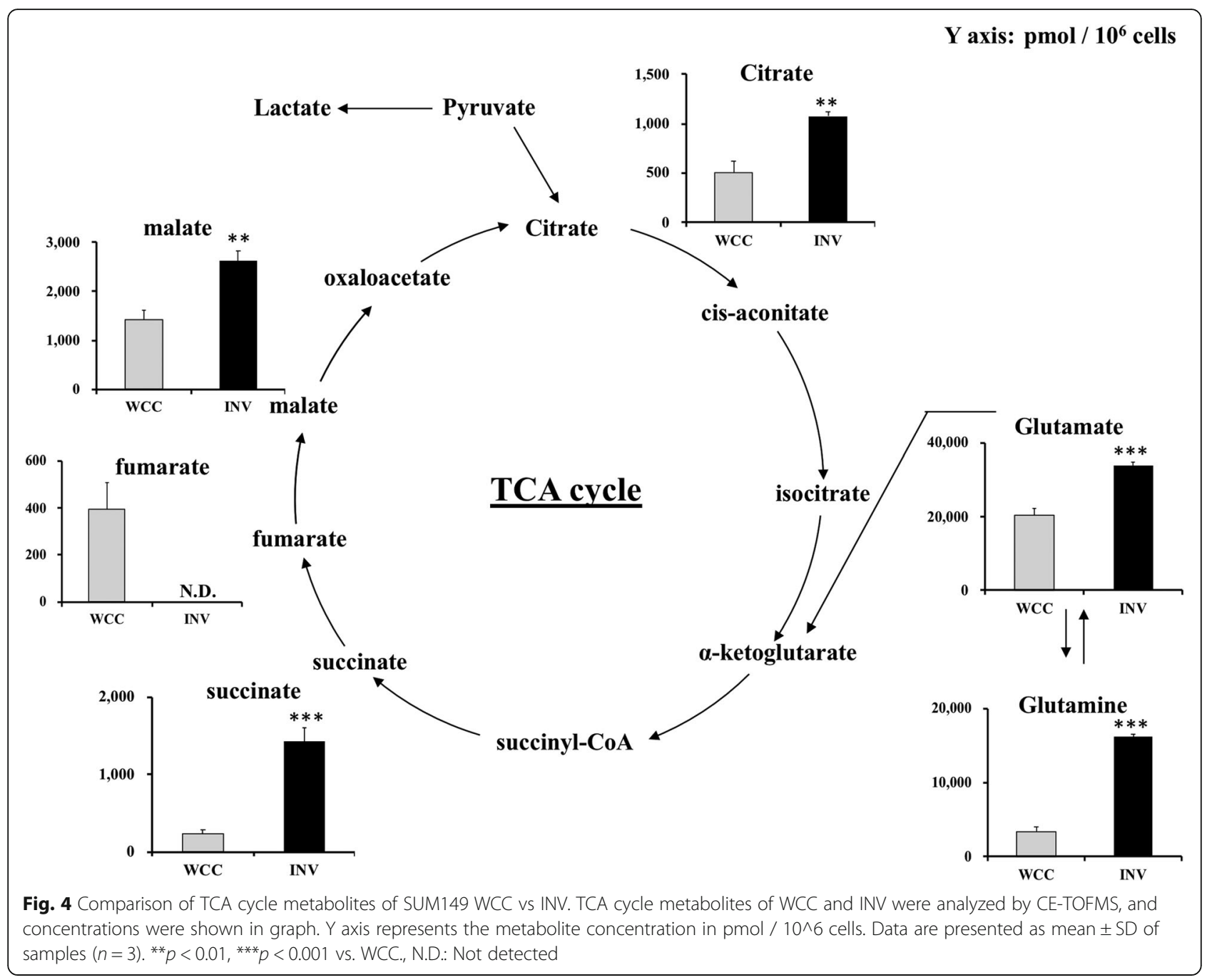

assay. First, we delineated the 2-DG dose requirement for inhibition of glycolysis versus cellular toxicity. If we used the level of 2-DG which blocks cell viability, then we could not examine the effect of de-activated glycolysis on the invasiveness because the cells had already succumbed. Thus, we chose lower 2-DG concentrations, 0.3 and $1 \mathrm{mM}$, compared to higher concentrations used in other studies focusing on the effect of 2-DG on blocking cell viability; Cheng et al. showed $5 \mathrm{mM}$ 2-DG was effective in reducing viability of pancreatic cancer cells, AsPC-1 and PANC-1 [39], Lucantoni et al. reported $10 \mathrm{mM}$ 2-DG was effective in reducing the number of colonies of $\mathrm{BC}$ cell lines, MCF7 and HDQ-PI [40], and Valera et al. reported that $5 \mathrm{mM}$ 2-DG was non-toxic for bladder cancer cell line, but could effectively sensitize these cancer cells to other anti-cancer drugs [41]. We first confirmed that treatment of cells with 0.3 or $1 \mathrm{mM} 2$-DG for $16 \mathrm{~h}$ reduced lactate production by SUM149, MDA-MB-231, and HCC1937 cell lines
(Supplemental Figure 6A-B), suggesting that low concentration of 2-DG was sufficient to reduce glycolysis. Inhibition of glycolysis is known to reduce cell viability [12-15]. Thus, we next investigated the sensitivity of SUM149, MDA-MB-231, or HCC1937 to same concentrations of 2-DG (Fig. 6a-c). Adding 0.3 or $1 \mathrm{mM} \mathrm{2-DG} \mathrm{to} \mathrm{the} \mathrm{cul-}$ ture media for $16 \mathrm{~h}$, had no significant effects on reducing surviving fraction in MDA-MB-231 or HCC1937, but importantly, $1 \mathrm{mM}$ 2-DG significantly reduced the invasiveness of these cells (Fig. $6 \mathrm{~b}-\mathrm{c}$ ). In the case of SUM149, $1 \mathrm{mM}$ 2-DG was already toxic, and hence reduced both surviving fraction and the invasion (Fig. 6a), but the level of reduction was much more drastic in invasion, compared to those observed in surviving fraction. In conclusion, data indicated that glycolysis has important role in aggressive $\mathrm{BC}$ invasiveness, and lower dose of 2-DG, non-toxic to cell viability, was efficient to reduce $\mathrm{BC}$ cell invasiveness. 
A

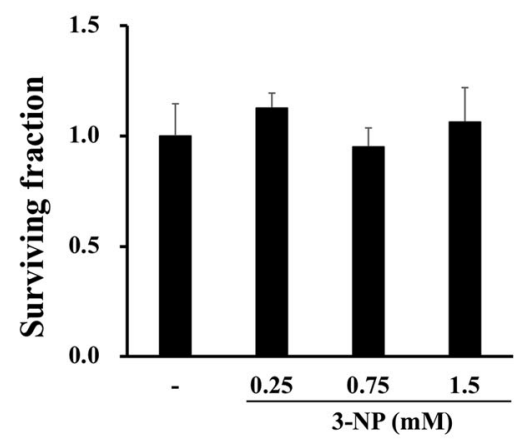

B

\section{MDA-MB-231}

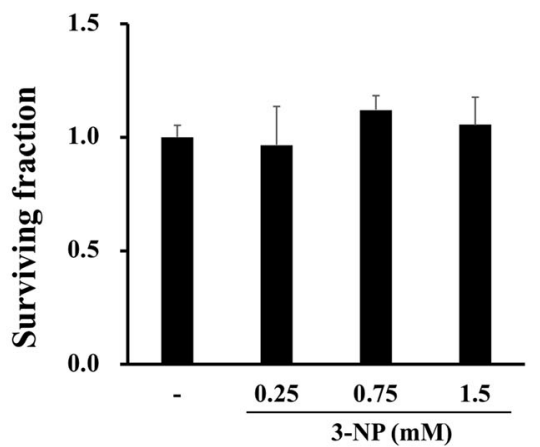

C

\section{HCC1937}

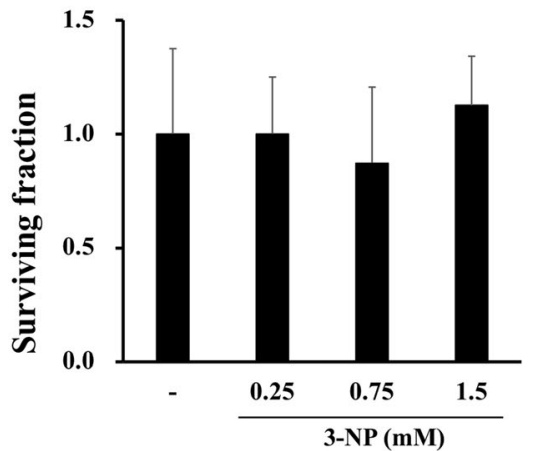

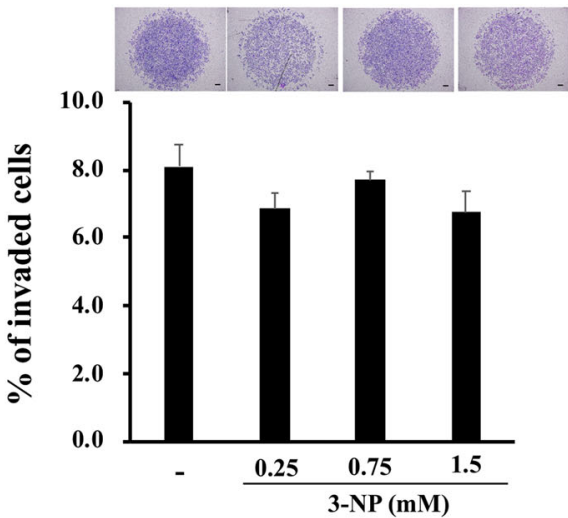
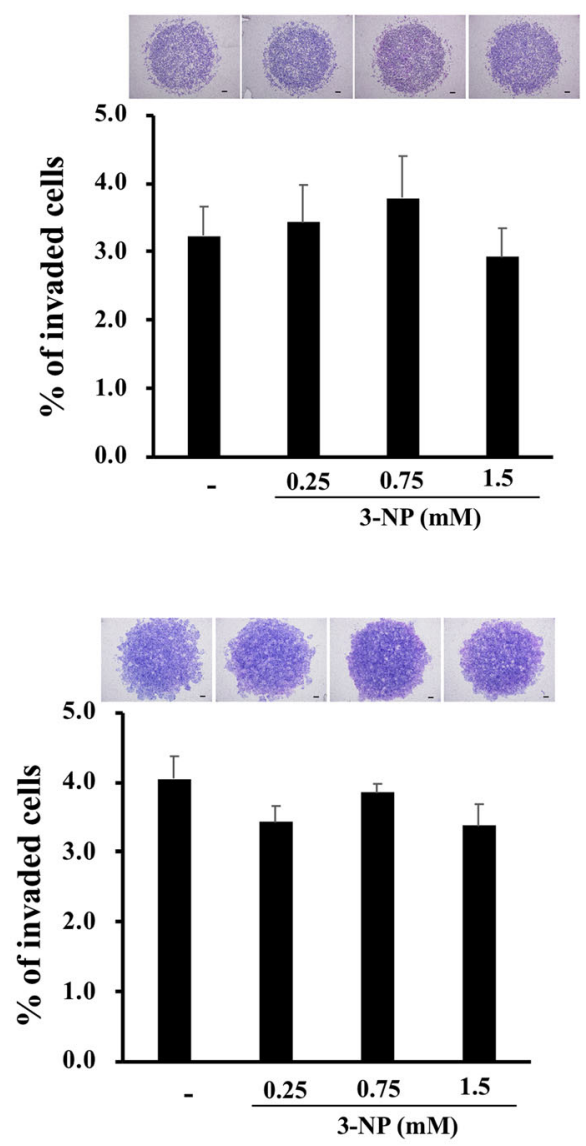

Fig. 5 Inhibitor for TCA cycle and ETC had no significant effects on BC invasiveness Cells were treated with 0.25, 0.75, or 1.5 mM 3-NA for 16 h, and surviving fraction, and invasiveness were studied. Ratio of surviving vs. control (no 3-NA treatment), and percent of invaded cells with representative image of invaded cells reached underneath of the transwell membrane were shown for SUM149 (a), MDA-MB-231 (b), and HCC1937 (c), respectively. Data are presented as mean \pm SDs of triplicate samples. Scale bar: $200 \mu \mathrm{m}$

\section{Discussion}

Most cancer cells rely on glycolysis even when oxygen is available, a phenomenon known as the Warburg effect [42]. Aggressive type of $B C$, viz. IBC and TNBC, have been shown to possess higher levels of glycolytic activity than ER+ breast cancer cells [43-46], however, the role of glycolysis specifically on their invasiveness is still unclear. In this study, we establish that INV from an IBC 


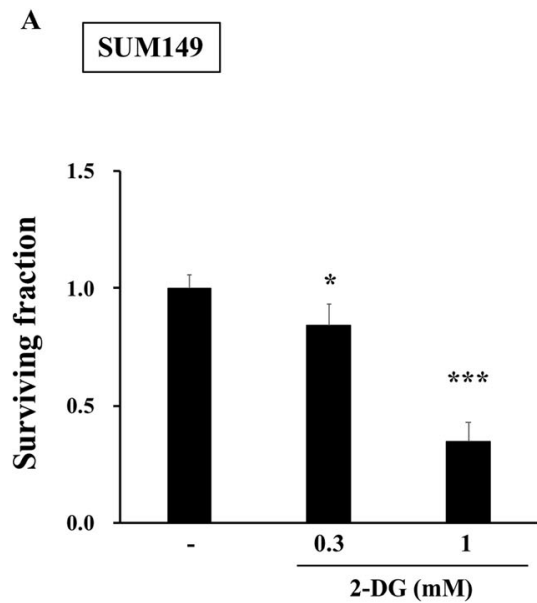

B

$$
\text { MDA-MB-231 }
$$

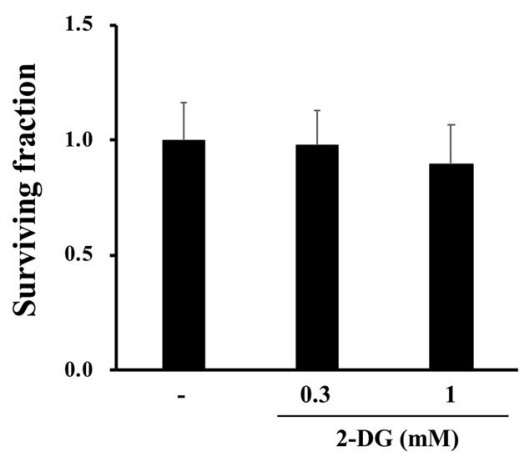

C

$$
\text { HCC1937 }
$$

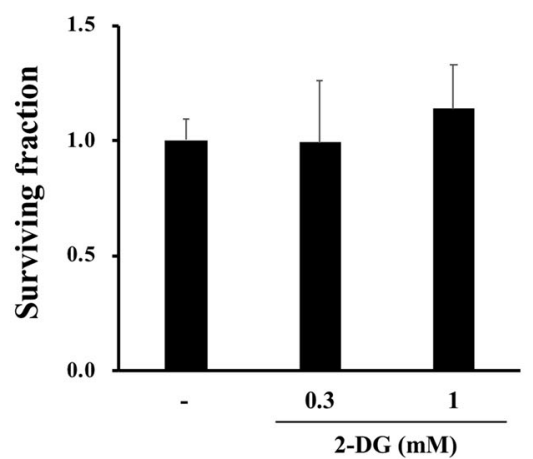

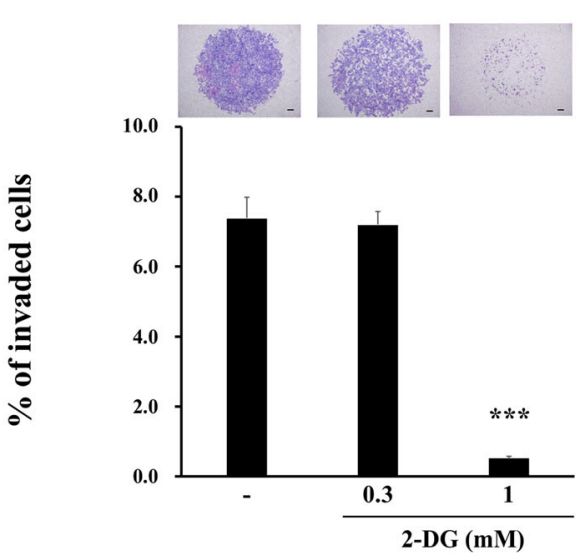
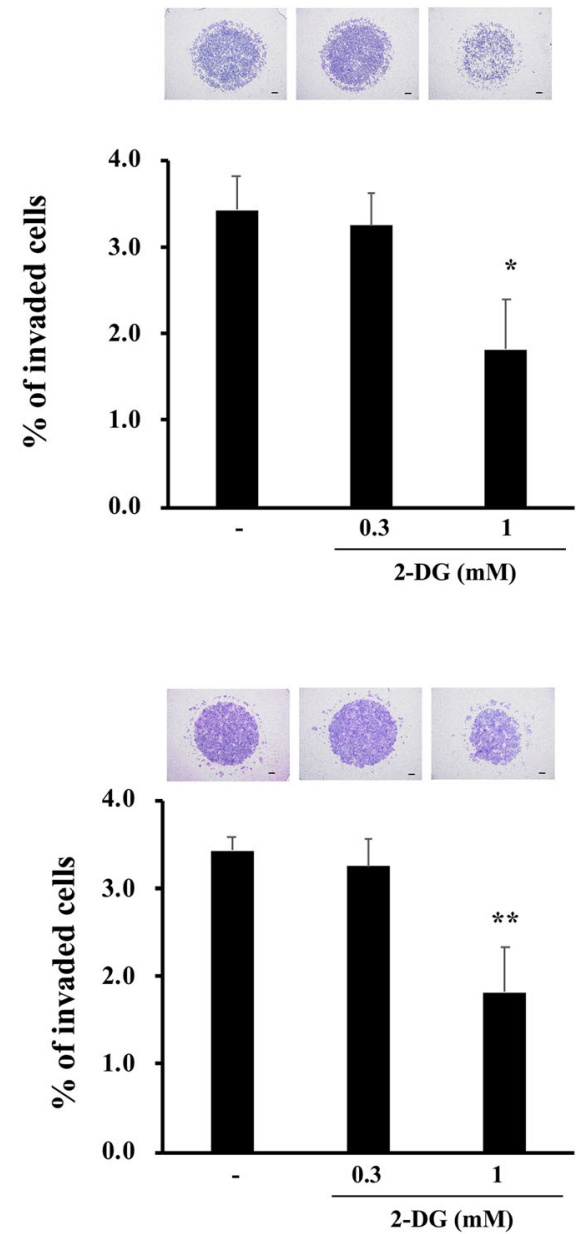

Fig. 6 Low dose of glycolysis inhibitor, 2-DG, diminished BC invasion Cells were treated with 0.3 or 1 mM 2-DG for 16 h, and surviving fraction, and invasiveness were determined. Ratio of surviving vs. control (no 2-DG treatment), and percent of invaded cells with representative image were shown for SUM149 (a), MDA-MB-231 (b), and HCC1937 (c), respectively. Data are presented as mean \pm SDs of triplicate samples. ${ }^{*} p<0.05$, ${ }^{* *} p<0.01,{ }^{* * *} p<0.001$. Scale bar: $200 \mu \mathrm{m}$

cell line had a persistently hyper-invasive phenotype. Such INV showed upregulation of glucose uptake, and were effectively targeted using a glycolysis inhibitor, 2-
DG. Several earlier studies have shown the ability of 2DG to block cancer growth [11-15, 47]. However, many of the clinical trials using 2-DG were discontinued due 
to the adverse side effects caused by the high doses of 2DG [11, 18]. Importantly, the concentration of 2-DG that we used in this study, $1 \mathrm{mM}$, is five times lower than the doses used in recent studies focusing on blocking cancer cell growth $(\geq 5 \mathrm{mM})$ [39-41], and $1 \mathrm{mM}$ was shown as non-toxic on cell survival [41]. In accordance, we observed that $1 \mathrm{mM}$ of 2-DG did not reduce cell survival of MDA-MB-231 and HCC1937 cell lines, but of note, it was significantly effective in blocking their invasion. Sadhbh O'Neill et al have reported that 2-DG is effective to inhibit migration and invasion ability of invasive $\mathrm{BC}$ subclone, Hs578T, but they used much higher concentration of 2-DG i.e., $15 \mathrm{mM}$ (15 times the dose used in the current study), and have not focused on the effect of 2-DG with lower dose [19]. The associated side effects of such a high dose of 2-DG would impede its use in clinical trials. However, lower doses of 2-DG which can still block cancer invasiveness, as we have shown here in aggressive BC cell lines, could be effectively applied as adjuvants to other anti-cancer therapies.

Several reports have shown that cancer cells have functional TCA cycle and ETC [4, 20, 21], concordantly, we observed that invading cells that move outward from spheroids embedded in collagen gel exhibited high mitochondrial membrane potential, suggesting that they possessed functional ETC. Blocking TCA and ETC with pharmacological inhibitor treatment diminished mitochondrial membrane potential, but it had no significant effects on blocking their invasion, indicating that TCA and ETC were less important than glycolysis to drive $\mathrm{BC}$ invasiveness. Glutamine can be a primary source fueling the TCA cycle $[22,23]$. A recent study has shown that GLS inhibitor was effective in diminishing cell growth by limiting influx of glutamine derivatives into the TCA cycle, but this effect was only detected in the cells which have high levels of GLS, suggesting that the role of glutamine for TCA cycle is cell line-specific [48]. In this study, we used glutamine free media or GLS1 inhibitor (CB-839) to investigate the role of glutamineTCA cycle pathway in SUM149. However, the no significant change was observed on their invasiveness. As expected from this data and previous literature, expression of GLS was low in SUM149 cells compared to other BC cells (data not shown) hence, inhibition of GLS1 had no effect in these cells. Also, the INV cells produce higher levels of all nonessential amino acids compared to WCC cells (Supplemental Figure 4) and could potentially fuel TCA through anaplerosis even in the absence of glutamine in the media [49].

Several studies have revealed that metformin is effective in blocking growth of aggressive cancer, including TNBC $[50,51]$. Metformin has been used to treat type II diabetes, and its function is the inhibition of mitochondrial membrane complex I [51]. Blocking of mitochondrial membrane complex I decreases proton-driven synthesis of ATP, causing cellular energetic stress and activation of AMPK, which in turn impairs cell proliferation [51]. Thus, mitochondrial respiration system may be important for the cancer cell growth, rather than for the invasiveness. In addition, it is well known that many of the amino acids are synthesized from TCA cycle intermediates [49], which were important source for cell living or may be for invasion. In this study, we found that most of the amino acid levels were significantly increased in INV compared to WCC (Supplemental Figure 4). Inhibiting mitochondrial respiration complex II with $0.75 \mathrm{mM}$ or $1.5 \mathrm{mM} 3$-NA for $16 \mathrm{~h}$ did not reduce survival of SUM149, MDA-MB-231, and HCC1937 in this study. However, in the case of MDA-MB-468, the least aggressive of the three TNBC cell lines, interestingly, treatment with the same doses of 3$\mathrm{NA}$, for $16 \mathrm{~h}$ drastically diminished cell growth and we were unable to collect the cells to use for the further invasion assay (data not shown). Thus, mitochondrial respiration system or TCA cycle may have significant role in cancer growth on certain cell types. The role of TCA cycle or ETC in SUM149, MDA-MB-231, and HCC1937 will be further delineated in future studies. However, it is now clear that although the TCA is not critical to the invasive process, they also have an active TCA cycle (through anaplerosis) which provides for cellular energy needs for sustenance, while glycolysis caters to the need for fast energy production required for invasion to occur within the nutrient deprived tumor conditions.

Epithelial mesenchymal transition (EMT) confers metastatic properties to cancer cells by increasing mobility, invasion, and metastasis [52, 53]. Interestingly, SNAI1, the transcription factor that represses Ecadherin expression (the marker of EMT induction), also enhances gene expression patterns that promote glucose uptake and glycolysis [54]. Although we have not determined the expression of E-cadherin in SUM149 INV, it is possible, given the higher invasiveness and higher glycolytic rate, that SUM149 INV was also in the mesenchymal state, similar to our previous report about INV established from human pancreatic cell line, PANC-1, that showed higher ability than WCC, to invade and metastasize in mice, exhibited reduced E-cadherin expression with induction of pro-metastatic genes [29].

\section{Conclusion}

Intra-tumor heterogeneity can regulate cancer progression, resistance to therapy, and relapse [55, 56]. Development of effective therapeutic strategies that target the invasion-metastasis cascade depends on an in-depth understanding of the fundamental differences between cancer cells that exhibit the invasive phenotype versus the non-invasive phenotype. In this study, we established 
that the SUM149 INV sub-population exhibited a persistent phenotype that was hyperinvasive, and of note, we have clearly demonstrated that inhibiting glycolysis with lower, non-cytotoxic doses of 2-DG was effective in diminishing invasiveness of aggressive $\mathrm{BC}$ cell lines. Appropriate combinations of tumoricidal agents such as ionizing radiation and chemotherapeutic drugs with low dose of 2-DG can potentially provide unique opportunities to selectively destroy tumors and block invasionmetastasis cascade, and are expected to reduce toxicity to normal tissues and significantly enhance the therapeutic efficacy in aggressive BC such as IBC and TNBC.

\section{Supplementary information}

Supplementary information accompanies this paper at https://doi.org/10. 1186/s12885-020-07414-y.

Additional file 1: Supplemental Figure 1. Full-length blot images used for Figure 3.

Additional file 2: Supplemental Figure 2. Mitochondrial membrane potential of SUM149 invading cells.

Additional file 3: Supplemental Figure 3. Effects of 3-NP on mitochondrial membrane potential.

Additional file 4: Supplemental Figure 4. Levels of amino acids in WCC and INV.

Additional file 5: Supplemental Figure 5. Glutamine had no significant effects on SUM149 invasiveness.

Additional file 6: Supplemental Figure 6. Lactate measurement Additional file 7: Table 1. List of metabolites measured in WCC or INV of SUM149.

\section{Abbreviations}

2-DG: 2-deoxy-D-glucose; 2-NBDG: 2-Deoxy-2-[(7-nitro-2,1,3-benzoxadiazol-4yl)amino]-D-glucose; 3-NA: 3-Nitropropionic acid; BC: Breast cancer; CETOFMS: Capillary electrophoresis-time-of-flight mass spectrometry; EMT: Epithelial-to-mesenchymal transition; ETC: Electron transport chain; FBS: Fetal bovine serum; G6P: Glucose-6-phosphate; G3P: Glycerol-3phosphate; GLS1: Glutaminase 1; IBC: Inflammatory breast cancer; INV: Invaded cells; MFI: Mean fluorescent intensity; PCA: Principal component analysis; PDH: Pyruvate dehydrogenase; PPDH: Phosphorylated-pyruvate dehydrogenase; pPDH S232: Phosphor-Pyruvate Dehydrogenase E1-alpha subunit Ser232; pPDH S239: Phosphor-Pyruvate Dehydrogenase E1-alpha subunit Ser239; pPDH S300: Phosphor-Pyruvate Dehydrogenase E1-alpha subunit Ser300; RPMI: Roswell Park Memorial Institute; SGLT: Sodium/Dglucose cotransporter; TCA cycle: Tricarboxylic acid cycle; TNBC: Triple negative breast cancer; WCC: Whole cultured cells

\section{Acknowledgements}

We are grateful to our colleagues from Stem Cell Biology Group of the National Institutes for Quantum and Radiological Science and Technology in Japan for providing expertise discussions that greatly assisted the research. We also thank all colleagues from Quantitative Redox Sensing Group for helpful assistance to carry out our research smoothly. We thank the crew of KOKEN CO., LTD for making custom version of 3D Ready Atelocollagen, phenol red-free collagen solution.

\section{Authors' contributions}

MF designed the experiments, performed most of the experimental works, data analysis, and prepared the manuscript. KI performed sample preparation for the metabolome analysis, performed the part of invasion assay experiment and immunoblotting experiment. VS and DW analyzed the part of metabolome data, and wrote the manuscript. MK analyzed the part of invasion assay data. KK performed sample preparation for the metabolome analysis. All authors read and approved the final manuscript.

\section{Funding}

This work was supported, in part by Fund for the Grant-in-Aid for Scientific Research (C) (grant no. 19 K08111 to MF) from the Japan Society for the Promotion of Science. This research was supported in part by the Intramural Research Program of the NIH, National Cancer Institute, Center for Cancer Research, Laboratory of Cancer Immunometabolism (D.A.W., V.S.). The content of this publication does not necessarily reflect the views or policies of the Department of Health and Human Services, nor does mention of trade names, commercial products, or organizations imply endorsement by the US Government. The funder had no role in designing the study, in collection, analysis, and interpretation of data, or in writing the manuscript.

Availability of data and materials

Not applicable.

Ethics approval and consent to participate

Cell lines used in this study did not require ethics approval for their use.

\section{Consent for publication}

Not applicable.

\section{Competing interests}

The authors declare that they have no competing financial interests.

\section{Author details}

${ }^{1}$ Department of Basic Medical Science for Radiation Damages, National Institute of Radiological Sciences, NIRS, National Institute for Quantum and Radiological Science and Technology, QST, 4-9-1, Anagawa, Inage-ku, Chiba-shi, Chiba-ken, Japan. ${ }^{2}$ Department of Radiation Oncology, Tokyo Women's Medical University, Tokyo, Japan. ${ }^{3}$ Laboratory of Cancer Immunometabolism, Center for Cancer Research, National Cancer Institute, National Institutes of Health, Frederick, MD, USA.

Received: 17 June 2020 Accepted: 15 September 2020

Published online: 29 September 2020

\section{References}

1. Tao Z, Shi A, Lu C, Song T, Zhang Z, Zhao J. Breast cancer: epidemiology and etiology. Cell Biochem Biophys. 2015;72:333-8.

2. Kleer CG, van Golen KL, Merajver SD. Molecular biology of breast cancer metastasis. Inflammatory breast cancer: clinical syndrome and molecular determinants. Breast Cancer Res. 2000;2:423-9.

3. Al-Mahmood S, Sapiezynski J, Garbuzenko OB, Minko T. Metastatic and triple-negative breast cancer: challenges and treatment options. Drug Deliv Transl Res. 2018;8:1483-507.

4. Kreuzaler P, Panina Y, Segal J, Yuneva M. Adapt and conquer: metabolic flexibility in cancer growth, invasion and evasion. Mol Metab. 2020;33:83101.

5. Vander Heiden MG. Targeting cancer metabolism: a therapeutic window opens. Nat Rev Drug Discov. 2011;10:671-84.

6. Semenza GL. HIF-1 and tumor progression: pathophysiology and therapeutics. Trends Mol Med. 2002;8(Suppl 4):S62-7.

7. Marín-Hernández A, Gallardo-Pérez JC, Rodríguez-Enríquez S, Encalada R, Moreno-Sánchez R, Saavedra E. Modeling cancer glycolysis. Biochim Biophys Acta. 1807;2011:755-67.

8. Gillies RJ, Robey I, Gatenby RA. Causes and consequences of increased glucose metabolism of cancers. J Nucl Med. 2008;49(Suppl 2):24S-42S.

9. Ferreira LM. Cancer metabolism: the Warburg effect today. Exp Mol Pathol. 2010;89:372-80.

10. Pelicano H, Martin DS, Xu RH, Huang P. Glycolysis inhibition for anticancer treatment. Oncogene. 2006;25:4633-46.

11. Dwarakanath B, Jain V. Targeting glucose metabolism with 2-deoxy-Dglucose for improving cancer therapy. Future Oncol. 2009;5:581-5.

12. Wokoun U, Hellriegel M, Emons G, Gründker C. Co-treatment of breast cancer cells with pharmacologic doses of 2-deoxy-D-glucose and metformin: starving tumors. Oncol Rep. 2017;37:2418-24.

13. Cao J, Cui S, Li S, Du C, Tian J, Wan S, Qian Z, Gu Y, Chen WR, Wang G. Targeted cancer therapy with a 2-deoxyglucose-based adriamycin complex. Cancer Res. 2013;73:1362-73. 
14. Zhang D, Li J, Wang F, Hu J, Wang S, Sun Y. 2-Deoxy-D-glucose targeting of glucose metabolism in cancer cells as a potential therapy. Cancer Lett. 2014; 355:176-83.

15. Zhang F, Aft RL. Chemosensitizing and cytotoxic effects of 2-deoxy-Dglucose on breast cancer cell. J Cancer Res Ther. 2009;5(Suppl 1):S41-3.

16. Dwarakanath BS, Singh D, Banerji AK, Sarin R, Venkataramana NK, Jalali R, Vishwanath PN, Mohanti BK, Tripathi RP, Kalia VK, et al. Clinical studies for improving radiotherapy with 2-deoxy-D-glucose: present status and future prospects. J Cancer Res Ther. 2009;5(Suppl 1):S21-6.

17. Stein M, Lin H, Jeyamohan C, Dvorzhinski D, Gounder M, Bray K, Eddy S, Goodin S, White E, Dipaola RS. Targeting tumor metabolism with 2deoxyglucose in patients with castrate-resistant prostate cancer and advanced malignancies. Prostate. 2010;70:1388-94.

18. Raez LE, Papadopoulos K, Ricart AD, Chiorean EG, Dipaola RS, Stein MN, Rocha Lima CM, Schlesselman JJ, Tolba K, Langmuir VK, et al. A phase I dose-escalation trial of 2-deoxy-D-glucose alone or combined with docetaxel in patients with advanced solid tumors. Cancer Chemother Pharmacol. 2013;71:523-30.

19. O'Neill S, Porter RK, McNamee N, Martinez VG, O'Driscoll L. 2-Deoxy-Dglucose inhibits aggressive triple-negative breast cancer cells by targeting glycolysis and the cancer stem cell phenotype. Sci Rep. 2019;9:3788.

20. Gogvadze V, Orrenius S, Zhivotovsky B. Mitochondria in cancer cells: what is so special about them? Trends Cell Biol. 2008;18:165-73.

21. Vaupel P, Mayer A. Availability, not respiratory capacity governs oxygen consumption of solid tumors. Int J Biochem Cell Biol. 2012:44:1477-81.

22. Altman BJ, Stine ZE, Dang CV. From Krebs to clinic: glutamine metabolism to cancer therapy. Nat Rev Cancer. 2016;16:619-34.

23. Zhang J, Pavlova NN, Thompson CB. Cancer cell metabolism: the essential role of the nonessential amino acid, glutamine. EMBO J. 2017:36:1302-15.

24. Ishikawa K, Hayashi J. A novel function of mtDNA: its involvement in metastasis. Ann N Y Acad Sci. 2010;1201:40-3.

25. Giampazolias E, Tait SW. Mitochondria and the hallmarks of cancer. FEBS J. 2016;283:803-14

26. Karasawa K, Fujita M, Shoji Y, Horimoto $Y$, Inoue T, Imai T. Biological effectiveness of carbon-ion radiation on various human breast cancer cell lines. J Cell Sci Ther. 2014:5:5.

27. Fujita M, Imadome K, Endo S, Shoji Y, Yamada S, Imai T. Nitric oxide increases the invasion of pancreatic cancer cells via activation of the PI3K-AKT and RhoA pathways after carbon ion irradiation. FEBS Lett. 2014;588:3240-50.

28. Fujita M, Imadome $\mathrm{K}$, Imai T. Metabolic characterization of invaded cells of the pancreatic cancer cell line, PANC-1. Cancer Sci. 2017;108:961-71.

29. Fujita M, Somasundaram V, Basudhar D, Cheng RYS, Ridnour LA, Higuchi $H$, Imadome K, No JH, Bharadwaj G, Wink DA. Role of nitric oxide in pancreatic cancer cells exhibiting the invasive phenotype. Redox Biol. 2019;22:101158.

30. Soga T, Heiger DN. Amino acid analysis by capillary electrophoresis electrospray ionization mass spectrometry. Anal Chem. 2000;72:1236-41.

31. Soga T, Ueno Y, Naraoka H, Ohashi Y, Tomita M, Nishioka T. Simultaneous determination of anionic intermediates for Bacillus subtilis metabolic pathways by capillary electrophoresis electrospray ionization mass spectrometry. Anal Chem. 2002;74:2233-9.

32. Soga T, Ohashi Y, Ueno Y, Naraoka H, Tomita M, Nishioka T. Quantitative metabolome analysis using capillary electrophoresis mass spectrometry. J Proteome Res. 2003;2:488-94.

33. Sugimoto M, Wong DT, Hirayama A, Soga T, Tomita M. Capillary electrophoresis mass spectrometry-based saliva metabolomics identified oral, breast and pancreatic cancer-specific profiles. Metabolomics. 2010;6:7895.

34. Araki R, Hoki Y, Suga T, Obara C, Sunayama M, Imadome K, Fujita M, Kamimura S, Nakamura M, Wakayama S, Nagy A, Wakayama T, Abe M. Genetic aberrations in iPSCS are introduced by a transient G1/S cell cycle checkpoint deficiency. Nat Commun. 2020;11:197.

35. Hong SM, Lee YK, Park I, Kwon SM, Min S, Yoon G. Lactic acidosis caused by repressed lactate dehydrogenase subunit B expression down-regulates mitochondrial oxidative phosphorylation via the pyruvate dehydrogenase (PDH)-PDH kinase axis. J Biol Chem. 2019;294:7810-20.

36. Wielert-Badt S, Lin JT, Lorenz M, Fritz S, Kinne RKH. Probing the conformation of the sugar transport inhibitor Phlorizin by 2D-NMR, molecular dynamics studies, and Pharmacophore analysis. J Med Chem. 2000;43:1692-8.
37. Zorova LD, Popkov VA, Plotnikov EY, Silachev DN, Pevzner IB, Jankauskas SS, Babenko VA, Zorov SD, Balakireva AV, Juhaszova M, Sollott SJ, Zorov DB. Mitochondrial membrane potential. Anal Biochem. 2018;552:50-9.

38. Sun F, Huo X, Zhai Y, Wang A, Xu J, Su D, Bartlam M, Rao Z. Crystal structure of mitochondrial respiratory membrane protein complex II. Cell. 2005;121:1043-57.

39. Cheng Y, Diao D, Zhang H, Guo Q, Wu X, Song Y, Dang C. High glucoseinduced resistance to 5 -fluorouracil in pancreatic cancer cells alleviated by 2-deoxy-D-glucose. Biomed Rep. 2014;2:188-92.

40. Lucantoni F, Dussmann H, Prehn JHM. Metabolic targeting of breast cancer cells with the 2-Deoxy-D-glucose and the mitochondrial bioenergetics inhibitor MDIVI-1. Front Cell Dev Biol. 2018:6:113.

41. Valera V, Ferretti MJ, Prabharasuth DD, Chaimowitz M, Choudhury M, Phillips $J$, Konno S. Is targeting glycolysis with 2-deoxyglucose a viable therapeutic approach to bladder cancer? Int J Cancer Ther Oncol. 2017;5:511.

42. Warburg O. On the origin of cancer cells. Science. 1956;123:309-14.

43. Choi J, Jung WH, Koo JS. Metabolism-related proteins are differentially expressed according to the molecular subtype of invasive breast cancer defined by surrogate immunohistochemistry. Pathobiology. 2013;80:41-52.

44. Pelicano H, Zhang W, Liu J, Hammoudi N, Dai J, Xu RH, Pusztai L, Huang P. Mitochondrial dysfunction in some triple-negative breast cancer cell lines: role of mTOR pathway and therapeutic potential. Breast Cancer Res. 2014;16:434.

45. Lanning NJ, Castle JP, Singh SJ, Leon AN, Tovar EA, Sanghera A, MacKeigan JP, Filipp FV, Graveel CR. Metabolic profiling of triple-negative breast cancer cells reveals metabolic vulnerabilities. Cancer Metab. 2017;5:6.

46. Wynn ML, Yates JA, Evans CR, Van Wassenhove LD, Wu ZF, Bridges S, Bao L, Fournier C, Ashrafzadeh S, Merrins MJ, Satin LS, Schnell S, Burant CF, Merajver SD. RhoC GTPase is a potent regulator of glutamine metabolism and N-Acetylaspartate production in inflammatory breast cancer cells. J Biol Chem. 2016;291:13715-29.

47. Pajak B, Siwiak E, Sołtyka M, Priebe A, Zieliński R, Fokt I, Ziemniak M, Jaśkiewicz A, Borowski R, Domoradzki T, Priebe W. 2-Deoxy-d-glucose and its analogs: from diagnostic to therapeutic agents. Int J Mol Sci. 2019;21:234

48. Koch K, Hartmann R, Tsiampali J, Uhlmann C, Nickel AC, He X, Kamp MA, Sabel M, Barker RA, Steiger HJ, Hänggi D, Willbold D, Maciaczyk J, Kahlert UD. A comparative pharmaco-metabolomic study of glutaminase inhibitors in glioma stem-like cells confirms biological effectiveness but reveals differences in target-specificity. Cell Death Dis. 2020;6:20.

49. Owen OE, Kalhan SC, Hanson RW. The key role of anaplerosis and cataplerosis for citric acid cycle function. J Biol Chem. 2002;277:30409-12.

50. Liu B, Fan Z, Edgerton SM, Deng XS, Alimova IN, Lind SE, Thor AD. Metformin induces unique biological and molecular responses in triple negative breast cancer cells. Cell Cycle. 2009;8:2031-40.

51. Luengo A, Sullivan LB, Heiden MG. Understanding the complex-l-ty of metformin action: limiting mitochondrial respiration to improve cancer therapy. BMC Biol. 2014;2:82.

52. Kang $H$, Kim H, Lee $S$, Youn $H$, Youn B. Role of metabolic reprogramming in epithelial-mesenchymal transition (EMT). Int J Mol Sci. 2019;20:2042.

53. Mittal V. Epithelial mesenchymal transition in tumor metastasis. Annu Rev Pathol. 2018;13:395-412.

54. Dong C, Yuan T, Wu Y, Wang Y, Fan TW, Miriyala S, Lin Y, Yao J, Shi J, Kang T, Lorkiewicz P, St Clair D, Hung MC. Loss of FBP1 by snail-mediated repression provides metabolic advantages in basal-like breast cancer. Cancer Cell. 2013;23:316-31.

55. Stanta G, Bonin S. Overview on clinical relevance of intra-tumor heterogeneity. Front Med. 2018;5:85.

56. Janiszewska M, Tabassum DP, Castaño Z, Cristea S, Yamamoto KN, Kingston NL, Murphy KC, Shu S, Harper NW, Del Alcazar CG, Alečković M, Ekram MB, Cohen O, Kwak M, Qin Y, Laszewski T, Luoma A, Marusyk A, Wucherpfennig KW, Wagle N, Fan R, Michor F, McAllister SS, Polyak K. Subclonal cooperation drives metastasis by modulating local and systemic immune microenvironments. Nat Cell Biol. 2019;21:879-88.

\section{Publisher's Note}

Springer Nature remains neutral with regard to jurisdictional claims in published maps and institutional affiliations. 